\title{
Recent Progress in Cell Reprogramming Technology for Cell Transplantation Therapy
}

\author{
Toru YAMASHITA ${ }^{1}$ and Koji ABE $^{1}$ \\ ${ }^{1}$ Department of Neurology, Okayama University Graduate School of Medicine, \\ Dentistry and Pharmaceutical Sciences, Okayama, Okayama
}

\begin{abstract}
The discovery of induced pluripotent stem (iPS) cells opened the gate for reprogramming technology with which we can change the cell fate through overexpression of master transcriptional factors. Now we can prepare various kinds of neuronal cells directly induced from somatic cells. It has been reported that overexpression of a neuron-specific transcriptional factors might change the cell fate of endogenous astroglia to neuronal cells in vivo. In addition, some research groups demonstrated that chemical compound can induce chemical-induced neuronal cells, without transcriptional factors overexpression. In this review, we briefly review recent progress in the induced neuronal (iN) cells, and discuss the possibility of application for cell transplantation therapy.
\end{abstract}

Key words: induced pluripotent stem cells, induced neuronal cells, in vivo direct reprogramming, chemical-induced neuronal cells, stroke

\section{Introduction}

Stroke is the second leading cause of death in the world, and results in a drastic reduction in the quality of life. However, effective therapeutic method is now very limited, especially in the chronic phase of a stroke, therefore a novel therapeutic strategy for the chronic phase of a stroke is now required. Recently, the discovery of induced pluripotent stem (iPS) cells opened the gate for stroke regenerative therapy, because iPS cell can produce patient-derived neurons. In addition, recently direct reprogramming methods has been established. Both induced neuronal stem (iNS) cells and induced neuronal (iN) cells, can be directly produced from somatic cells.

In this review, we briefly review recent progress in the iN cells, and discuss the possibility of application for cell transplantation therapy of post-stroke patients.

\section{I. iPS cells technology}

In 2006, Prof. Yamanaka firstly established murine iPS cells by overexpressing four transcriptional factors (Oct3/4, Sox2, c-Myc, and Klf4) in mouse fibroblasts. Of note, they found that these key transcription factors (TFs) from 20 candidates

Received November 30, 2015; Accepted January 12, 2016 were strongly expressed in embryonic stem (ES) cells. ${ }^{1)}$ iPS cells can retain high replication competence and pluripotency, and can differentiate into various kinds of cells. The iPS cells characteristics were very similar to ES cells, indicating that overexpression of key TFs can change cell fate. Since iPS cells can be induced from a patient's skin fibroblasts, there are no immunoreactive and/ or ethical issues, which are found in ES cells. Therefore, iPS cells are believed to be a promising cell resource for cell transplantation/replacement therapy. Several scientific papers have demonstrated that human iPS cells-derived neuronal stem cells/ neuronal progenitors, when transplanted into the stroke murine model brain, showed a therapeutic effect such as the recovery of motor function. For example, Oki et al. produced long-term self-renewing neuroepithelial-like stem cells from adult human fibroblast-derived iPS cells, and transplanted them into the stroke mouse model. They found that motor function had already recovered at the time point of first week after transplantation. Functional recovery was observed soon after cell transplantation, then the observed therapeutic effect was regarded to be derived from neurotrophic factors released from transplanted cells. ${ }^{2)}$ It is well known that only the replacement of injured neuron cannot contribute for stroke recovery. Transplantation of exogenous 
cells including mesenchymal stem cells, which is also promising cell resource, is also currently being investigated for stroke and other neurological disorders. ${ }^{3,4)}$

\section{Discovery of iN cells}

Some Japanese research groups have started or planned to conduct clinical transplantation therapy trials using iPS cells for age-related macular degeneration, spinal cord injury, and Parkinson disease. ${ }^{5)}$ However, iPS cells might form tumors, especially in pathological conditions such as post-stroke. ${ }^{6)}$ In addition, it is likely to be difficult to monitor tumor formation for more than 2 years, because animal model cannot survive longer period. Therefore, a new technology and strategy supplying neuronal cells to damaged brains, is required. Research findings of iPS cells suggested that overexpression of ES cell-specific TFs could convert fibroblasts to ES cell-like iPS cells. From this finding, many researchers have overexpressed neuron-specific TFs in skin/ lung fibroblasts, in order to convert these fibroblasts into neuronal cells. In 2010, Wernig et al. firstly established murine iN cells by overexpressing three neuron-specific TFs (Ascl1, Brn2, and Myt1l) in mouse fibroblasts. They found that these iN cells showed a glutamatergic neuronal phenotype with action potential, as recorded by electric patchclump analysis. ${ }^{7)}$ Until now various kinds of iN cells, such as dopaminergic neurons and motor neurons, have been reported (Table 1). ${ }^{8-23)}$ Interestingly, Ascl1 appears to be a key factor in the induction of iN cells, and the specific combination of Ascl1 plus other factors can convert somatic cells to specific neuronal cells. In terms of cell transplantation therapy, it has already been reported that induced dopaminergic neurons transplantation increased the level of striatal dopamine, showing a therapeutic effect in 6-hydroxydopamine (6-OHDA)treated rats. ${ }^{8)}$ Compared with iPS cells, iN cells are regarded as safer, and easier to induce within a relatively short time frame. But the iN cell conversion process stops cell cycle making it difficult to prepare sufficient quantities of iN cells for cell transplantation therapy. iNS cells were developed to overcome this problem. In 2012, Han et al. found that a combination of TFs (Sox2, Brn4, Klf4, c-Myc) that successfully induced mouse fibroblasts

Table 1 Scientific reports showing direct reprogramming from fibroblasts to neuronal cells

\begin{tabular}{|c|c|c|c|}
\hline Target cells & Original cells & $\begin{array}{l}\text { Combination of transcriptional factors for } \\
\text { reprogramming }\end{array}$ & Reference \\
\hline \multirow{10}{*}{$\begin{array}{l}\text { Glutamatergic } \\
\text { neurons }\end{array}$} & mice fibroblasts & Ascl1, Brn2, Myt1 & Vierbuchen et al., 2010 \\
\hline & mice hepatocytes & Ascl1, Brn2, Myt1 & Marro et al., 2011 ${ }^{10)}$ \\
\hline & human fibroblasts & Ascl1, Brn2, Myt1, NeuroD1 & Pang et al., 201111) \\
\hline & human fibroblasts & Ascl1, Brn2, Myt1, Olig2, Zic1 & Qiang et al., 2011 ${ }^{12)}$ \\
\hline & human fibroblasts & Ascl1, Myt1, NeuroD2, miR-9/9*, and miR-124 & Yoo et al., 2011 ${ }^{13)}$ \\
\hline & human fibroblasts & Brn2, Myt1, miR-124 & Ambasudhan et al., 2011 ${ }^{14)}$ \\
\hline & astroglia in stab-injured & NeuroD1 & Guo et al., 2014 ${ }^{15)}$ \\
\hline & & CHIR99021, Forskolin, I-BET151, ISX9 & Li et al., 2015 21$)$ \\
\hline & mice fibroblasts & CHIR99021, Forskolin, VPA, Repsox, & Hu et al., 2015 22$)$ \\
\hline & human fibroblasts & SP600125, GO6983, Y-27632 & \\
\hline \multirow{3}{*}{$\begin{array}{l}\text { Dopaminergic } \\
\text { neurons }\end{array}$} & mice/human fibroblasts & Ascl1, Lmx1a, Nurr1 & Caiazzo et al., 2011 \\
\hline & mice fibroblasts & Ascl1, Lmx1a, Nurr1, Pitx3, Foxa2, En1 & Kim et al., 2011 \\
\hline & human fibroblasts & Ascl1, Brn2, Myt1, Lmx1a, FoxA2 & Pfisterer et al., 2011 ${ }^{17)}$ \\
\hline Motor neurons & mice/human fibroblasts & $\begin{array}{l}\text { Ascl1, Brn2, Myt1, NeuroD1, Lhx3, Hb9, } \\
\text { Isl1, Ngn2 }\end{array}$ & Son et al., 2011 ${ }^{18)}$ \\
\hline \multirow[t]{3}{*}{ Neural stem cells } & mice fibroblasts & Sox2, Brn2, FoxG1 & Lujan et al., 2011 ${ }^{19)}$ \\
\hline & mice fibroblasts & Sox2, Brn4/Pou3f4, Klf4, c-Myc, E47/Tcf3 & Han et al., 20129) \\
\hline & mice/human fibroblasts & Sox 2 & Ring et al., 2012 20 ) \\
\hline
\end{tabular}

Modified from Yamashita et al., 2014. ${ }^{23}$ 
directly to iNS cells.9) Han et al. evaluated the therapeutic effect of cell transplantation using iNS cells in the spinal cord injury rat model. They also found that engrafted iNS cells could differentiate into neuronal lineages with synapses, enhancing the recovery of locomotor function. ${ }^{24)}$ Therefore, iNS cells can be regarded as a promising cell resource candidate for cell transplantation/ replacement therapy (Fig. 1).

\section{Development of direct reprogramming technology}

Recently, a lot of novel findings in the field of iN cells are reported every year. In particular, in vivo direct conversion technology and chemical-induced neuronal (CiN) cells are attracting the most atten-
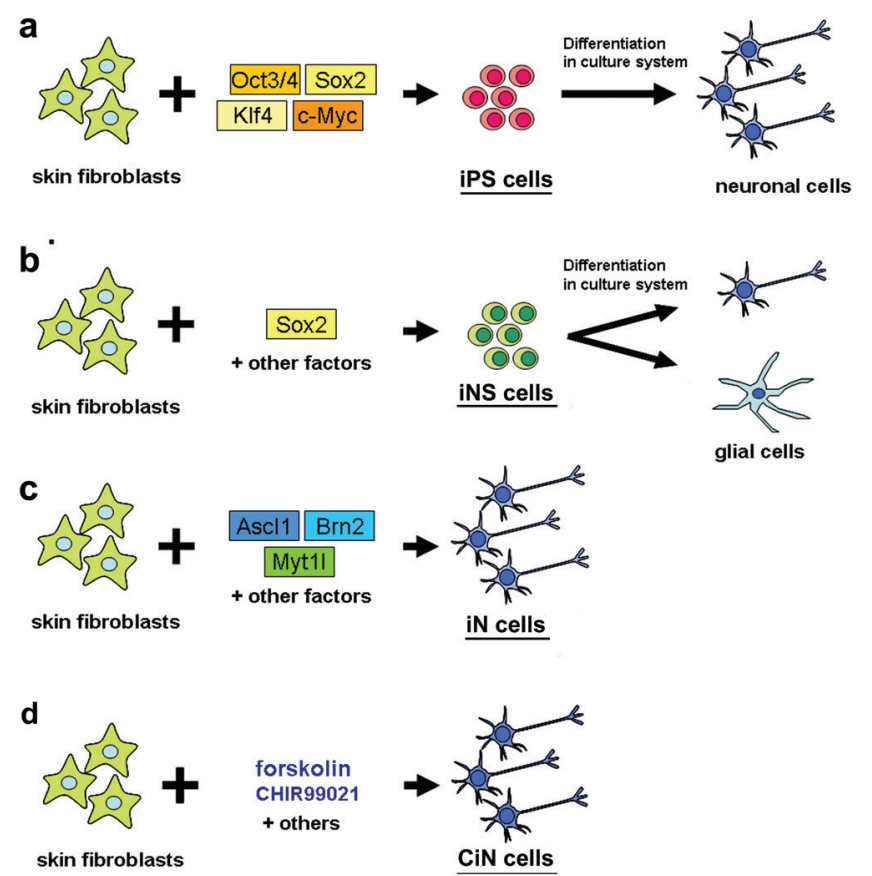

Fig. 1 Summary of induction of iPS cells, iNS cells, iN cells, and CiN cells. a: Overexpression of Oct3/4, Sox2, Klf4, and c-Myc can convert somatic cells such as skin fibroblasts into iPS cells. Neuronal cells can be obtained after differentiation in the cell culture system. b: Overexpression of Sox2 with other factors can convert skin fibroblasts into iNS cells. Both neuronal and glial lineages can be obtained from iNS cells. c: The combination of Asc1, Brn2, and Myt1l with other factors can directly convert skin fibroblasts into iN cells (direct reprogramming methods). d: The chemical cocktail of forskolin, CHIR99021, and other chemicals can directly convert skin fibroblasts into CiN cells (chemical direct reprogramming methods). CiN: chemical-induced neuronal, iN: induced neuronal, iNS: induced neuronal stem, iPS: induced pluripotent stem. (Modified from Yamashita et al., 2014.) ${ }^{23)}$ tion. In a clinical setting, the culture medium, including calf/bovine serum, can be problematic as they may be infectious materials against the human body. Thus, if endogenous non-neuronal cells such as astroglia can be converted to required neurons called as "in vivo direct conversion," it could be a simple and straightforward way of supplying required new neuronal cells to the injured brain. Until now, astroglia as well as pericytes have been reported to be directly reprogrammed into neuronal cells in cell culture systems. ${ }^{25,26)}$ In 2013, Torper et al. showed that endogenous mouse astroglia could be converted into NeuN-positive neuronal cells in vivo. $^{27)}$ In 2014, Guo et al. reported that reactive glial cells in the cortex of the stab-injured mice model could be directly reprogrammed into functional neurons in vivo by overexpressing a single neural TF, NeuroD1. ${ }^{15)}$ These findings suggested that in vivo direct reprogramming technology is a hopeful method supplying required neurons for the human central nervous system.

In 2015, two different research teams published that CiN cells could be established using a cocktail of chemical compounds including forskolin (a cyclic adenosine monophosphate agonist), and CHIR99021 (a glycogen synthase kinase 3 beta inhibitor) (Fig. 1). ${ }^{21,22)}$ In this method, mouse/ human skin fibroblasts were successfully converted to neuronal cells without overexpressing TFs, indicating that the chemical cocktail can replace previously reported reprogramming $\mathrm{TFs}$, leading to easier and more stable reprogramming methods that supply neuronal cells.

\section{Conclusion}

This review briefly highlights recent progress in the development of direct reprogramming technology for cell transplantation therapy. Especially in vivo direct reprogramming technology may be a simple and hopeful method as new cell replacement therapy, because cell preparation and transplantation are not required. Clinical trials using iPS cells are ongoing, but it is important to combine these technologies or to choose appropriate strategies depending on the target disease.

\section{Acknowledgments}

This work was partly supported by Grant-in-Aid for Scientific Research (B) 25293202, (C) 15K09316, Challenging Research 15K15527, Young Research 15K21181, and by Grants-in-Aid from the Research Committees (Mizusawa H, Nakashima K, Nishizawa M, Sasaki H, 
and Aoki M) from the Ministry of Health, Labour and Welfare of Japan.

\section{Conflicts of Interest Disclosure}

The authors declare no conflicts of interest.

\section{References}

1) Takahashi K, Yamanaka S: Induction of pluripotent stem cells from mouse embryonic and adult fibroblast cultures by defined factors. Cell 126: 663-676, 2006

2) Oki K, Tatarishvili J, Wood J, Koch P, Wattananit S, Mine Y, Monni E, Tornero D, Ahlenius H, Ladewig J, Brüstle O, Lindvall O, Kokaia Z: Human-induced pluripotent stem cells form functional neurons and improve recovery after grafting in stroke-damaged brain. Stem Cells 30: 1120-1133, 2012

3) Kuroda S, Houkin K: Translational challenge for bone marrow stroma cell therapy after stroke. Front Neurol Neurosci 32: 62-68, 2013

4) Tanna T, Sachan V: Mesenchymal stem cells: potential in treatment of neurodegenerative diseases. Curr Stem Cell Res Ther 9: 513-521, 2014

5) Okamoto S, Takahashi M: Induction of retinal pigment epithelial cells from monkey iPS cells. Invest Ophthalmol Vis Sci 52: 8785-8790, 2011

6) Yamashita T, Kawai H, Tian F, Ohta Y, Abe K: Tumorigenic development of induced pluripotent stem cells in ischemic mouse brain. Cell Transplant 20: 883-891, 2011

7) Vierbuchen T, Ostermeier A, Pang ZP, Kokubu Y, Südhof TC, Wernig M: Direct conversion of fibroblasts to functional neurons by defined factors. Nature 463: 1035-1041, 2010

8) Kim J, Su SC, Wang H, Cheng AW, Cassady JP, Lodato MA, Lengner CJ, Chung CY, Dawlaty MM, Tsai LH, Jaenisch R: Functional integration of dopaminergic neurons directly converted from mouse fibroblasts. Cell Stem Cell 9: 413-419, 2011

9) Han DW, Tapia N, Hermann A, Hemmer K, Höing S, Araúzo-Bravo MJ, Zaehres H, Wu G, Frank S, Moritz S, Greber B, Yang JH, Lee HT, Schwamborn JC, Storch A, Schöler HR: Direct reprogramming of fibroblasts into neural stem cells by defined factors. Cell Stem Cell 10: 465-472, 2012

10) Marro S, Pang ZP, Yang N, Tsai MC, Qu K, Chang HY, Südhof TC, Wernig M: Direct lineage conversion of terminally differentiated hepatocytes to functional neurons. Cell Stem Cell 9: 374-382, 2011

11) Pang ZP, Yang N, Vierbuchen T, Ostermeier A, Fuentes DR, Yang TQ, Citri A, Sebastiano V, Marro S, Südhof TC, Wernig M: Induction of human neuronal cells by defined transcription factors. Nature 476 : 220-223, 2011

12) Qiang L, Fujita R, Yamashita T, Angulo S, Rhinn H, Rhee D, Doege C, Chau L, Aubry L, Vanti WB, Moreno H, Abeliovich A: Directed conversion of
Alzheimer's disease patient skin fibroblasts into functional neurons. Cell 146: 359-371, 2011

13) Yoo AS, Sun AX, Li L, Shcheglovitov A, Portmann T, Li Y, Lee-Messer C, Dolmetsch RE, Tsien RW, Crabtree GR: MicroRNA-mediated conversion of human fibroblasts to neurons. Nature 476: 228-231, 2011

14) Ambasudhan R, Talantova M, Coleman R, Yuan $X$, Zhu S, Lipton SA, Ding S: Direct reprogramming of adult human fibroblasts to functional neurons under defined conditions. Cell Stem Cell 9: 113-118, 2011

15) Guo Z, Zhang L, Wu Z, Chen Y, Wang F, Chen G: In vivo direct reprogramming of reactive glial cells into functional neurons after brain injury and in an Alzheimer's disease model. Cell Stem Cell 14: 188-202, 2014

16) Caiazzo M, Dell’Anno MT, Dvoretskova E, Lazarevic D, Taverna S, Leo D, Sotnikova TD, Menegon A, Roncaglia P, Colciago G, Russo G, Carninci P, Pezzoli G, Gainetdinov RR, Gustincich S, Dityatev A, Broccoli V: Direct generation of functional dopaminergic neurons from mouse and human fibroblasts. Nature 476: 224-227, 2011

17) Pfisterer U, Kirkeby A, Torper O, Wood J, Nelander J, Dufour A, Björklund A, Lindvall O, Jakobsson J, Parmar M: Direct conversion of human fibroblasts to dopaminergic neurons. Proc Natl Acad Sci USA 108: 10343-10348, 2011

18) Son EY, Ichida JK, Wainger BJ, Toma JS, Rafuse VF, Woolf CJ, Eggan K: Conversion of mouse and human fibroblasts into functional spinal motor neurons. Cell Stem Cell 9: 205-218, 2011

19) Lujan E, Chanda S, Ahlenius H, Südhof TC, Wernig M: Direct conversion of mouse fibroblasts to selfrenewing, tripotent neural precursor cells. Proc Natl Acad Sci U S A 109: 2527-2532, 2012

20) Ring KL, Tong LM, Balestra ME, Javier R, AndrewsZwilling Y, Li G, Walker D, Zhang WR, Kreitzer AC, Huang Y: Direct reprogramming of mouse and human fibroblasts into multipotent neural stem cells with a single factor. Cell Stem Cell 11: 100-109, 2012

21) Li X, Zuo X, Jing J, Ma Y, Wang J, Liu D, Zhu J, Du X, Xiong L, Du Y, Xu J, Xiao X, Wang J, Chai Z, Zhao Y, Deng H: Small-Molecule-Driven Direct Reprogramming of Mouse Fibroblasts into Functional Neurons. Cell Stem Cell 17: 195-203, 2015

22) Hu W, Qiu B, Guan W, Wang Q, Wang M, Li W, Gao L, Shen L, Huang Y, Xie G, Zhao H, Jin Y, Tang B, Yu Y, Zhao J, Pei G: Direct Conversion of Normal and Alzheimer's Disease Human Fibroblasts into Neuronal Cells by Small Molecules. Cell Stem Cell 17: 204-212, 2015

23) Yamashita T, Abe K: Direct reprogrammed neuronal cells as a novel resource for cell transplantation therapy. Cell Transplant 23: 435-439, 2014

24) Hong JY, Lee SH, Lee SC, Kim JW, Kim KP, Kim SM, Tapia N, Lim KT, Kim J, Ahn HS, Ko K, Shin CY, Lee HT, Schöler HR, Hyun JK, Han DW: Therapeutic potential of induced neural stem cells for 
spinal cord injury. J Biol Chem 289: 32512-32525, 2014

25) Addis RC, Hsu FC, Wright RL, Dichter MA, Coulter DA, Gearhart JD: Efficient conversion of astrocytes to functional midbrain dopaminergic neurons using a single polycistronic vector. PLOS ONE 6: e28719, 2011

26) Karow M, Sánchez R, Schichor C, Masserdotti G, Ortega F, Heinrich C, Gascón S, Khan MA, Lie DC, Dellavalle A, Cossu G, Goldbrunner R, Götz M, Berninger B: Reprogramming of pericyte-derived cells of the adult human brain into induced neuronal cells. Cell Stem Cell 11: 471-476, 2012
27) Torper O, Pfisterer U, Wolf DA, Pereira M, Lau S, Jakobsson J, Björklund A, Grealish S, Parmar M: Generation of induced neurons via direct conversion in vivo. Proc Natl Acad Sci USA 110: 7038-7043, 2013

Address reprint requests to: Koji Abe, $\mathrm{MD}, \mathrm{PhD}$, Department of Neurology, Okayama University Graduate School of Medicine, Dentistry and Pharmaceutical Sciences, 2-5-1 Shikata-cho, Okayama, Okayama 700-8558, Japan. e-mail: tooy@d1.dion.ne.jp 